\title{
Measuring Heart Rate During Exercise: From Artery Palpation to Monitors and Apps
}

\author{
Marcos Almeida, ${ }^{10}$ Altamiro Bottino, ${ }^{2}{ }^{\circledR}$ Plínio Ramos, ${ }^{3{ }^{\circledR}}$ Claudio Gil Araujo ${ }^{(\circledR)}$ \\ Universidade Federal de Sergipe,' São Cristóvão, SE - Brazil \\ Coordenação Científica do São Paulo Futebol Clube, ${ }^{2}$ São Paulo, SP - Brazil \\ Faculdade de Ciências Médicas e da Saúde de Juiz de Fora, ${ }^{3}$ Juiz de Fora, MG - Brazil \\ Exercise Medicine Clinic - CLINIMEX, Rio de Janeiro, RJ - Brazil
}

\section{Abstract}

The use of technology has increased tremendously, by means of more reliable, smaller, more accessible and specially more user-friendly devices, which provide a wider range of features, and promote significant benefits for the population and health professionals. It is in this context that monitors and apps for heart rate (HR) measurement have emerged. HR is a clinical vital sign of diagnostic and prognostic importance. In response to body movement, HR tends to increase, in a direct relationship with the intensity of exercise. HR was primarily measured by the count of arterial pulse, and recently, HR can be precisely measured by monitors, bracelets and smartphone apps capable to perform real-time measurements and storage of data. This paper aimed to make a brief and updated review on the theme, providing a broader view of advantages and limitations of these resources for HR measurement in exercise. HR monitors and apps use basically two types of technology, optical sensor (photoplethysmography) and electrical signal from the heart. In general, these devices have shown good accuracy in measuring HR and HR variability at rest, but there are differences between brands and models considering the type, mode and intensity of exercise. HR measurements by monitors and smartphone apps are simple, accessible and may help cardiologists in the monitoring of the intensity of aerobic exercise, focusing on health promotion and on primary and secondary prevention of cardiovascular diseases.

\section{Keywords}

Exercise; Heart Rate, Palpation; Exercise Therapy; Fitness Trackers; Monitoring, Physiologic.

\section{Introduction}

The use of technology in health has exponentially increased, fostering the use of monitors and mobile apps for heart rate (HR) measurement. Recent equipment and resources for HR monitoring are better, more accurate, more compact, cheaper and more user-friendly, and provide a wider range of features and greater recording and storage capacity. Therefore, be it in-person or via telemedicine, these technologies have the potential to generate benefits to the population and to facilitate and be a complement to medical services. ${ }^{1}$

HR is the most important vital sign; it is one of the most remote indicator of health since early civilizations. ${ }^{2}$ The assessment of HR can be clinically used in case of suspected pulmonary embolism and acute infections. ${ }^{3} \mathrm{HR}$ is expressed as beats per minute (bpm), and is modulated by autonomic nervous system. ${ }^{4}$ From a clinical and epidemiological point of view, life expectancy seems to be inversely correlated with $\mathrm{HR}$ at rest and positively correlated with maximum heart rate during exercise, magnitude of HR decrease after exercise, and the combination of these three variables, as assessed by HR gradient during exercise, proposed by Brazilian authors. ${ }^{5}$

In response to body movement, HR tends to rise, causing an increase in cardiac output, and transport of oxygen and substrates to the tissues, and removal of $\mathrm{CO}_{2}$ and wastes from them. ${ }^{2}$ In maximal incremental exercise, HR tends to gradually increase until its maximum

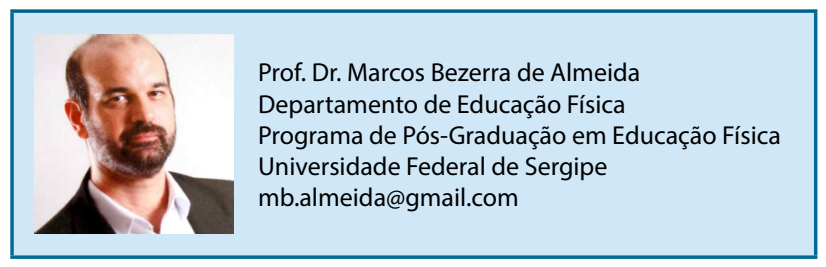

Mailing Address: Marcos Almeida

Universidade Federal de Sergipe - Avenida Marechal Rondon - Sn. Postal Code: 49100-000, São Cristóvão, SE - Brazil.

E-mail: mb.almeida@ufs.br 
value. Maximum $\mathrm{HR}$, measured by laboratory and field tests, or estimated by predictive equations, tend to be linearly attenuated with ageing, ${ }^{6}$ especially after the age of 35 years. $^{7}$ There are many predictive equations for maximum HR in aging. The equation: maximum $\mathrm{HR}=208-0.7 \mathrm{x}$ age (years) was validated in a Brazilian population. ${ }^{8}$ However, the margin of error is quite large, and easily exceeds at any given age and in $5 \%$ or more of the individuals.

Therefore, when using $\mathrm{HR}$ as a tool for the assessment and prescription of exercise, it should be directly measured from an individual rather than predicted by equations. ${ }^{8}$ Measured maximum HR can then be used to define, in a better and more precise way, the range of intensity of an exercise training program. ${ }^{9}$

However, despite its importance in clinical practice and in exercise prescription and monitoring, there are no standardized guidelines to measure HR. ${ }^{10}$ On the other hand, recent technological advances have made HR measurement more accessible and popular due to high availability of monitors, armbands, and even smartphone apps. ${ }^{2,3}$ Since 2012, more than 30 new products for HR measurement have been launched, ${ }^{11}$ and this number tends to increase. In this regard, this paper presents a brief and updated overview about the use of devices and monitors for HR measurement in exercise and in clinical cardiology.

HR in exercise and sports: a brief contextualization

\section{Resting condition}

Resting HR is often used as an indicator of cardiorespiratory or aerobic fitness. Cross sectional studies have shown that cardiorespiratory fitness is inversely related to resting HR in adolescents, ${ }^{12}$ adults, ${ }^{13}$ and elderly. ${ }^{14}$ In untrained women, aerobic training reduced resting HR regardless of age $(<41$ or 41-60 years) of participants or duration of intervention they were exposed to $\left(<3,4-6\right.$ or $>6$ months). ${ }^{15}$ Although this association may be attributed, at least in part, to increased resting cardiac vagal activity, ${ }^{16}$ electrophysiologic changes intrinsic to the sinus node may also occur in many physically trained individuals. ${ }^{17}$

\section{Cardiovascular drift}

The balance between cardiac output and oxygen requirement during exercise may require a cardiovascular adjustment known as cardiovascular drift, which negatively influences performance. ${ }^{18}$ In practical terms, it is important to identify this phenomenon, since HR tends to increase with prolonged effort performed at the same level, particularly if sustained for 30 minutes or longer or under unfavorable thermal conditions. ${ }^{19}$ Two hypotheses have been suggested for this phenomenon, which involves an increase in HR associated with a reduction in systolic volume. First, dehydration has been proposed as the mechanism responsible for blood volume reduction, leading to impaired venous return and reduced end-diastolic volume and, consequently reduced systolic volume (Figure 1). In this process, cardiac output would depend on increased HR. ${ }^{20}$ More recently, Coyle and Gonzáles-Alonso ${ }^{21}$ proposed a inverse pathway, in which HR acceleration would limit the time for determination of the end-diastolic volume, resulting in lower systolic volume. In fact, during prolonged exercise, it is possible that HR increases regardless of variations in exercise intensity. Monitoring of HR during exercise facilitates the control of exercise intensity and maintenance of performance.

\section{Maximal exercise}

During incremental maximal exercise, HR increases in response to gradual decrease in cardiac vagal activity until its complete suppression at peak effort, at the same time that adrenergic stimulation becomes the protagonist of autonomic control of HR. ${ }^{23}$ Maximal HR is limited by hypoxia, regardless of age and sex, but this reduction is more evident in individuals with lower cardiorespiratory fitness. ${ }^{24}$ Nevertheless, a limitation to physiological increase in HR in response to increased activity is known as chronotropic incompetence..$^{25}$ This may also result from a late response of HR acceleration, instability or lowered response to exercise intensity. ${ }^{26}$

Considering that the increment in HR is the main responsible for the increase in cardiac output and thus for the possibility of performing an aerobic exercise, ${ }^{25}$ the chronotropic incompetence turns out to be a restrictive factor to exercise performance, as in some patients with heart failure, ${ }^{27}$ and is associated with increased mortality risk. ${ }^{28}$

\section{Post-exercise recovery}

Post-exercise HR recovery, or decrement, is the difference between HR at the end of exercise (maximal or submaximal) and HR at 1 minute or 2-5 minutes after exercise, and is similar in men and women. ${ }^{29}$ 


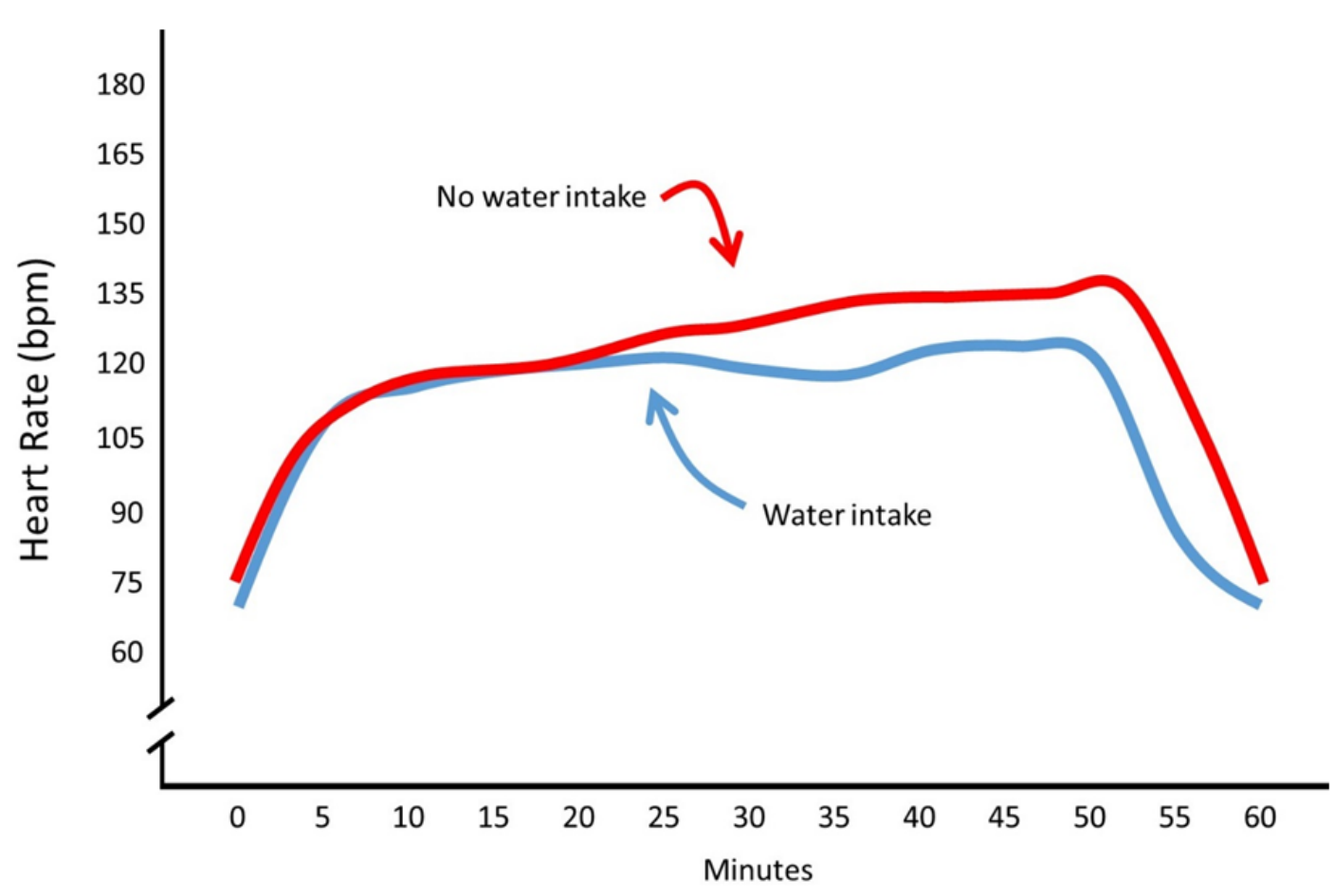

Figure 1 - Hypothetical example of heart rate variation in response to prolonged, constant-load aerobic exercise and dehydration. Even at constant exercise intensity, heart rate varies throughout the first two minutes of exercise, and the steady state is affected by dehydration, with an increase in heart rate. Adapted from Chagas et al..$^{22}$ and Araújo. ${ }^{19}$

Epidemiological data have shown that a slight decrease in HR after exercise represents an increased risk of mortality $\cdot{ }^{30,31}$ However, although $\mathrm{HR}$ recovery tends to be faster in men and women with higher maximal $\mathrm{VO}_{2}$, there is a weak association between these two physiological variables, where regression model explains no more that $11 \%$ of HR variation. ${ }^{32}$ The association between initial and final transient periods of HR recovery is not strong either. ${ }^{33}$ On the other hand, analysis of post-exercise HR recovery may contribute to the identification of athletes of different sports with favorable autonomous nervous system adaptive changes. ${ }^{34}$

\section{History of HR measurement in exercise}

\section{Palpating arteries or auscultating the heart}

The simplest and most original way to measure HR is to palpate the arteries, and the most commonly used for this purpose are the radial, the common carotid and the superficial temporal arteries. The time of palpation may vary from 6 to 60 seconds, but it is important to highlight that the shorter the time, the greater the error, since the number of heartbeats is multiplied by a factor to obtain the number of heartbeats in one minute. For example, if the time of palpation was 6 seconds, the number of heartbeats is multiplied by 10 and the multiplier represents the margin of error. ${ }^{35}$ On the other hand, a longer measurement time, or closer to 60 seconds, has lower margin of error but is more susceptible to autonomic modulation and other disturbances or artifacts, especially during or after exercise (Figure 2). ${ }^{4}$

\section{Monitors}

Obviously, it would be necessary something more efficient operationally, without stopping the run or other exercise to obtain a real-time measurement of HR, without mathematical calculations. The first devices had old technology optical sensors; the first versions were composed of wires connected to the panel of treadmills or similar devices, with sensors fixed under pressure on the digital pulp surface or the ear lobe, which were extremely sensitive to body motion during exercise. Thus, HR measures obtained by this method had low 


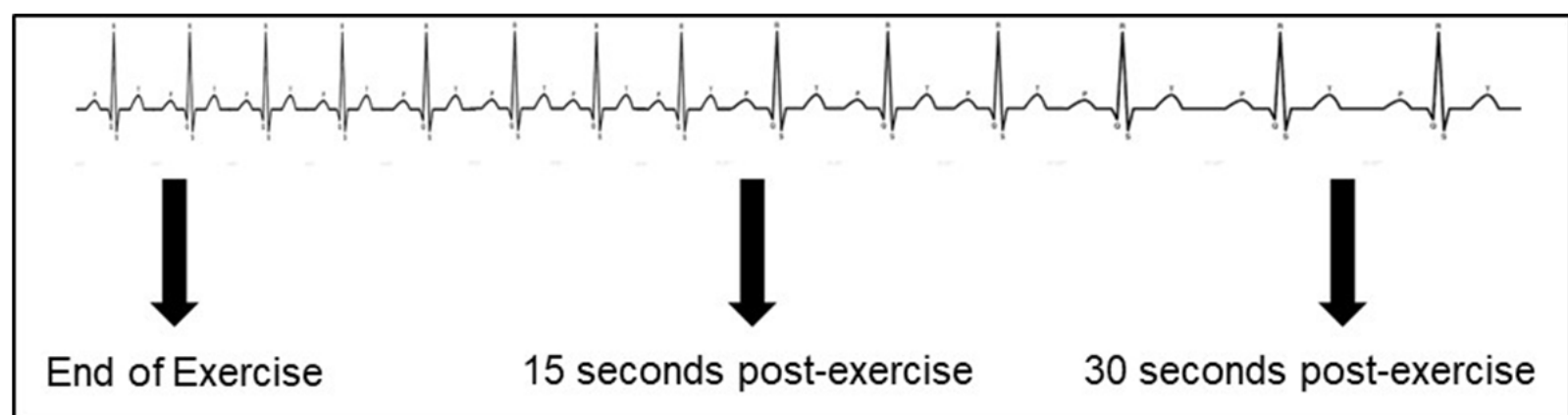

Figure 2 - Theoretical model of heart rate response after exercise, modulated by cardiac vagal reactivation during 30 seconds of digital palpation. We can see the widening of the time between the systoles (RR intervals at electrocardiography) at the end, and at 15 seconds and 30 seconds after exercise.

accuracy and reliability. Also, not rarely, the sensor was removed from the ear lobe during exercise because of a wider movement of the arms for example, affecting HR monitoring.

In the early 1970's, an exercise physiologist and future swimming coach, Dr. Robert Treffene, developed a handheld monitor with wires and electrodes that could be used by the coach outside the pool to check the HR of swimmers as soon as they stopped at the pool wall. ${ }^{35}$

At the end of the same decade, Professor Seppo Säynäjäkangas invented a HR monitor for Finland's national cross-country ski team to use while training. In 1977, he founded the Polar Electro $\mathrm{Oy}^{\circledR}$, a pioneer company in this field, based in Kempele, Finland. Only six years later, the first HR monitor became commercially available, the Polar Sport Tester PE 2000, ${ }^{35}$ that could be used by athletes and practitioners who wanted to obtain a more accurate HR measurement to adjust their training load. ${ }^{36}$ Due to modern technology, there are several brands and models of HR monitors available nowadays, with more sophisticated features, including higher memory capacity, stopwatches, time and pace alarms, estimator of energy expenditure, GPS, among others.

\section{Mobile apps}

In the study by Lee et al., ${ }^{37}$ the authors reported that HR monitors could be expensive and, therefore, not accessible to patients. In addition, HR monitors worn with elastic bands could cause discomfort and limit a wider use of these devices.
Therefore, considering the increasing use of smartphones in Brazil and in the world, mobile apps for HR measurement seem to be very interesting. The technology required to detect cardiac chronotropy encompasses from photoplethysmography (PPG) via smartphone cameras $^{38}$ to accessories, including smartphone cases containing ECG sensors. ${ }^{39}$ Therefore, mobile apps (and often associated watches and monitors) are capable not only to measure the HR but also to identify arrhythmias, such as atrial fibrillation. ${ }^{40}$ However, Coppetti et al. ${ }^{41}$ pointed out possible differences between HR measured by contact and noncontact PPG. The authors showed that non-contact PPGbased apps can show relatively high margin of errors (7 to $8 \mathrm{bpm}$ ), compared with errors varying from 2 to 4 of contact PPG-based apps.

\section{Heart rate monitors}

\section{What is a HR monitor?}

HR monitor is a device that allows the measurement and display of real-time HR data and, depending on the model, storage of data for posterior analysis. HR monitors have been widely used not only to evaluate aerobic performance but also to monitor the intensity of predominantly aerobic exercises. The monitors contain an elastic band with contact sensors (electrodes) that detect cardiac electrical activity (systoles) and send it to a receptor via radio waves, ${ }^{42}$ or optical sensors (PPG). Today, there are many models and brands of HR monitors available in the market, providing different features, from those with time of exercise and HR measurement on 
the display, until more sophisticated ones, that include GPS and performance indexes, such as pace, average pace throughout the route, cadence, among others. GPS devices obtain components that give external training loads greater importance, as well as wider diversity of measurements. Altimeters, gyroscopes, magnetometers, accelerometers, and inclinometers provide real-time information regarding direction, amount of $\mathrm{G}$-force, and vectors of force, allowing a precise control of variables that help to make better decisions.

Detection of HR by HR monitors occurs primarily by two types of technology, optical sensor (PPG) and ECG. While ECG-based HR monitors work with a chest strap (Figure 3), PPG-based monitors are wrist devices, although optical sensors have been adapted to products worn in other parts of the body, such as headphones, arm straps and even headbands. ${ }^{43}$

\section{Precision and accuracy of heart rate measurements} using HR monitors and apps

Cadmus-Bertram et al. ${ }^{44}$ highlighted the need of health professionals and general population to know the accuracy of HR monitors and apps for correct use of the devices. The authors recognized the difficulties inherent to the validation of these tools. In addition, with the rapid development of technology, there are many recent publications on $\mathrm{HR}$ devices that may have already been outperformed by others, ${ }^{41}$ notably in terms of updating of algorithms that are not well explained, i.e. it is unclear how HR measurement shown on the display was actually determined (sample frequency).
Besides, from an operational standpoint, it is not feasible to perform a comprehensive validation of all these devices considering all their possible applications. In this context, Cadmus-Bertram et al. ${ }^{45}$ reported that PPGbased HR monitors are accurate to measure HR at rest, but not during exercise. Also, Singh and Sittig ${ }^{46}$ reported discrepancies in the measurements of both resting and post-exercise HR (walking and running) obtained by a HR monitor as compared with a control measurement, indicating that the device being tested lost signal when HR was over $140 \mathrm{bpm}$. Although this is not a concern for most users of HR monitors and apps, and these devices do provide good and precise measurements for daily life application, clinical cardiologists should be aware that the measurements displayed by these devices may not be accurate.

Similar results were observed by Boudreaux et al., ${ }^{47}$ who compared eight different models/brands of HR monitors with a gold-standard method, a six-lead ECG measurement in resting conditions, during aerobic exercise of different intensity and resistance exercise. Although all monitors tested had good validity at rest, only three showed good accuracy $(r \geq 0,75)$ - the Apple Watch Series 2, the Polar H7 and the Bose SoundSport Pulse, highlighting that the last two did not have a wristwatch. The higher the exercise intensity, the lower the accuracy of the measurement, with a tendency of an underestimation of HR, in both aerobic and circuit resistance exercise. In addition, some of the monitors did not measure the HR in real time, with a 3-5 second delay. This is evident since HR tends to increase slightly
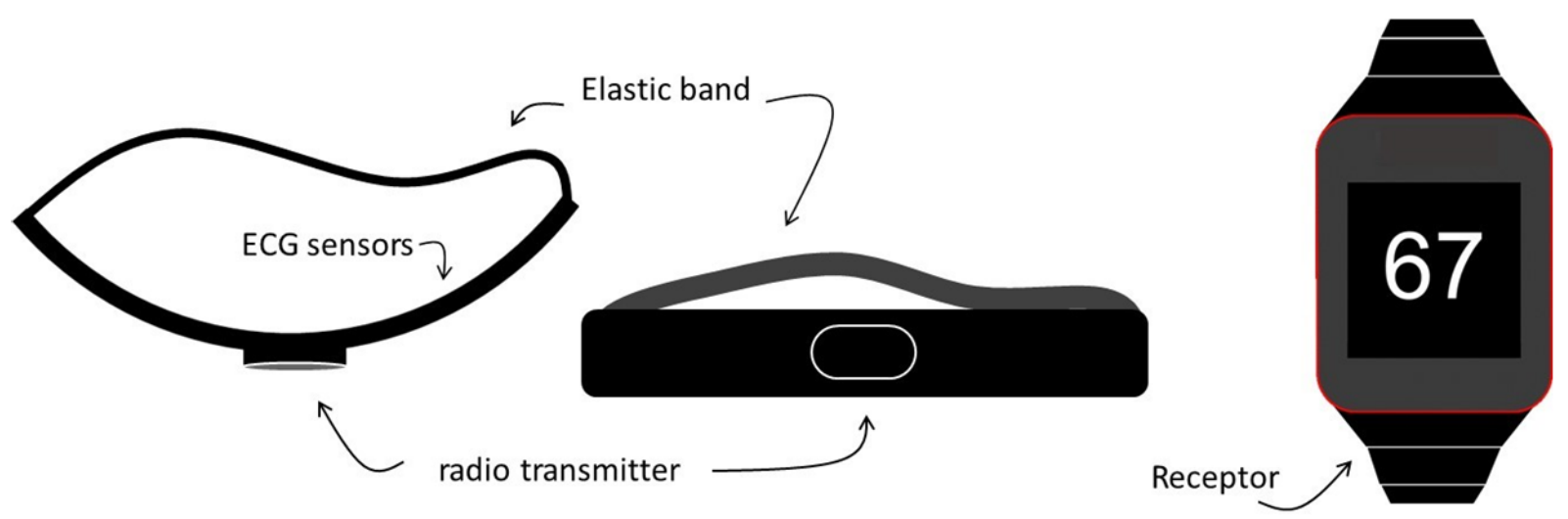

Figure 3 - Basic structural components of a radio telemetry heart rate monitor. 
in the first five seconds after a very high-intensity exercise, different from what is physiological and precisely identified by an objective measurement of $R R$ intervals at ECG. ${ }^{48}$

Horton et al. ${ }^{49}$ showed that the Polar M600 is validated for HR measurements in aerobic exercises, such as cycling, walking, jogging and running, but only during steady-state exercise, i.e., with relatively constant intensity. However, HR responses to circuit resistance exercise were, again, underestimated. Other models such as the Apple Watch 1 and the FitBit Charge HR were also shown to be able to measure HR properly, ${ }^{50,51}$ whereas the Garmin Forerunner 225 overestimated HR measurements during low-to-moderate walking and jogging on a treadmill, but obtained HR measurements similar to reference values during high-intensity exercise. ${ }^{51}$ The authors suggested that this could be explained by the fact that the Garmin Forerunner 225 had been developed for running, and not for walking exercise. It is also possible that technical difficulties are even higher in other types of aerobic exercises, such as swimming and rowing.

The findings described in this section should be interpreted with caution, and at least in part, considered in the context of clinical practice. For some measurements, although some statistical differences were observed between the HR monitor and ECG, they may not influence the reliability of monitors, since absolute differences were not greater than $2 \mathrm{bpm}$. In addition, the device settings should be not be ignored to avoid measurement errors..$^{52}$ Therefore, in general, HR monitors may be considered sufficiently accurate to be used during physical exercise for most individuals and most daily life conditions.

\section{Main applications in exercise}

\section{Common situations in exercise}

There are many situations where a real-time recording of the HR favors the control of the exercise intensity proposed. This is somewhat commonly seen at gyms, physical activity centers or even in outdoor settings.

For example, Eddolls et al..$^{53}$ suggested high-intensity interval training (known as HIIT) to children and adolescents, based on an intensity higher than $90 \%$ of maximum HR for improvement of health indicators. Although this exercise modality includes recovery intervals, these intervals are not sufficient to perform HR measurement, be it by palpation or auscultation.
In this context, the HR monitor provides an immediate feedback that facilitates the maintenance of exercise intensity within pre-established ranges.

In resistance exercises, the use of HR monitors is less frequent. However, Latella et al. ${ }^{54}$ suggested that the establishment of recovery time between sets based on HR responses may be one of the most effective strategies to optimize the results. During circuit resistance training, HR tends to be maintained at higher levels due to its shorter and more active intervals. Alcaraz et al., ${ }^{55}$ though, did not find differences in performance (repetition maximum and muscle power) between high-intensity resistance circuit training and traditional strength training. HR values registered (Polar S625X monitor) at the end of each exercise bout were similar between the two types of exercises, although decrease of HR was greater in intervals between the sessions of traditional training.

Barbosa-Netto et al. ${ }^{56}$ observed that, although the magnitude of HR responses depends on the intensity of exercise, HR kinetics was similar throughout a 10 repetitions set, with rapid acceleration in the first 10 seconds and attenuation in the last five seconds, followed by rapid recovery at the end of the last repetition. In these studies, HR monitor allowed the identification of responses that were easily obtained and interpreted.

\section{Field conditions and team monitoring}

The systematization of HR monitoring in trainings and games started in 1990 with soccer players. This strategy has been very effective in establishing training loads and compare them to physiological responses obtained during official matches and competitions. Also, it has helped the monitoring of the intensity of the training sessions (Figure 4). HR measurements were carried out using chest straps and wrist-based monitors during physical trainings, whereas in technical and tactical training and games, the signal was transmitted by telemetry, since according to the rules of the sport modality, players are not allow to wear wrist watches, rings, earrings and bracelets. The obvious reason for that was to allow the players to be as free as possible to move, and to be focused on the main goal of the training. Members of the coaching staff started to monitor players' HR in order to make adjustments in the intensity of the training and performance of matches.

Computers and tablets have become crucial instruments of biofeedback, comparably to chest straps. 


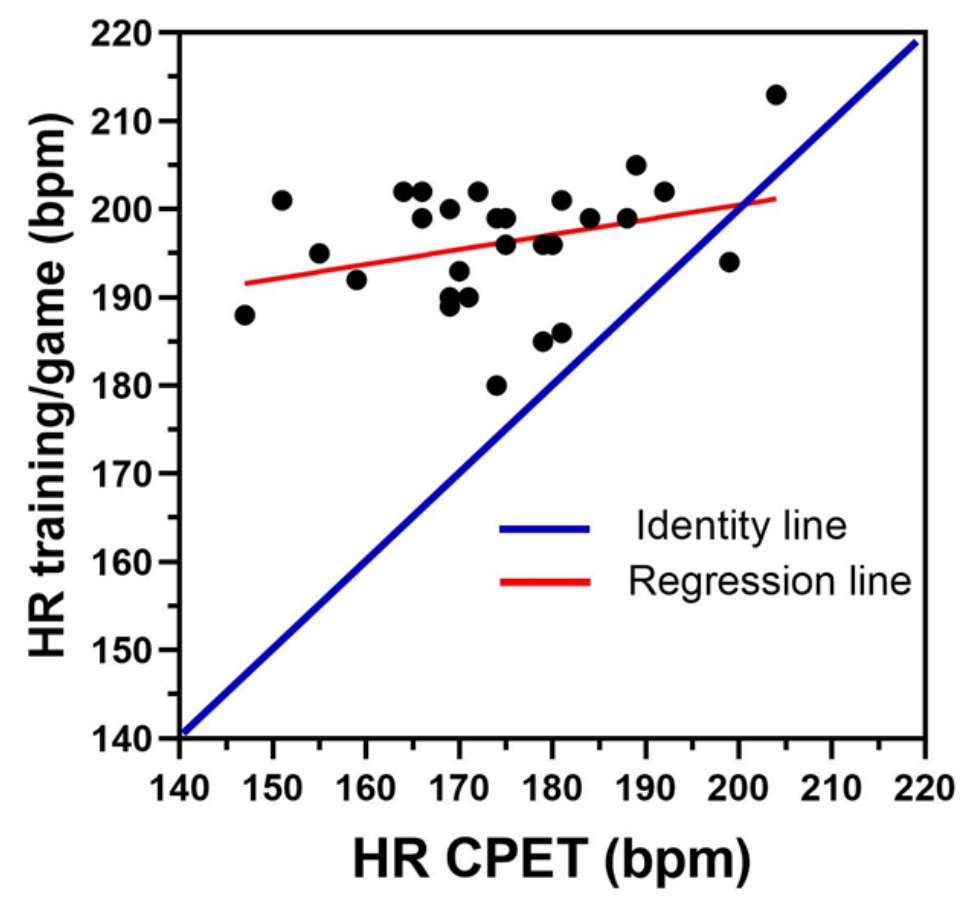

Figure 4 - Monitoring of heart rate in professional soccer players in a maximal incremental treadmill exercise test (November 2018 end of season) and in specific soccer-related activities (training and official matches) in January, February and March 2019 (Bottino, unpublished data); HR: heart rate; CPET: cardiopulmonary exercise test.

However, it was only in 2003 , during the $8^{\text {th }}$ annual congress of the European College of Sports Science held in Salzburg, Austria, that HR monitoring became one of the most important variables on internal load control, ${ }^{57}$ and the concepts of acute and chronic loads regarding stimuli and consequent adaptations emerged (Figure 5).

It is important to mention that, among all objective variables of exercise intensity, HR is, so far, the only variable that enables a real-time measurement and analysis. The other variables (hormones, metabolites, thermography etc.) require an interruption or ending of activity, training session or game for data collection and analysis. ${ }^{58}$ Consequently, a new generation of GPS (and one of the leading brand in the area), is at final testing stage to incorporate $\mathrm{HR}$ measurement as one of its components. ${ }^{59}$ This will allow an even closer integration of information with $\mathrm{HR}$ as a variable of training/game total load.

In field conditions, the use of apps that analyze HR alone may face some operational limitations. The signal coverage range is still small (approximately $60 \mathrm{~m}$ ), which is very limited considering the official soccer field size.
In addition, storage capacity is limited in the absence of available Bluetooth connection. This is a common situation when the team goes to the dressing rooms and become practically isolated in a Faraday shield due to the metallic structures of the beams and cladding of the facilities. Such interruption in signal transmission results in a nearly 15 minutes of recording loss, which could affect the information about the athletes' level of recovery after exercise.

This special limitation regarding Bluetooth communication does not occur when the signal is transmitted from the chest strap to the GPS, since the distance between these components is less than one meter. From the GPS unit, the signal is transmitted to external antennas in the field and then to satellites. Besides, GPS devices have enough storage capacity and, in case of signal loss during the match, the HR data can be recovered for further analysis.

\section{Potential clinical applications}

Considering that some of the HR monitors have a large sample rate and large capacity of data storage, it 


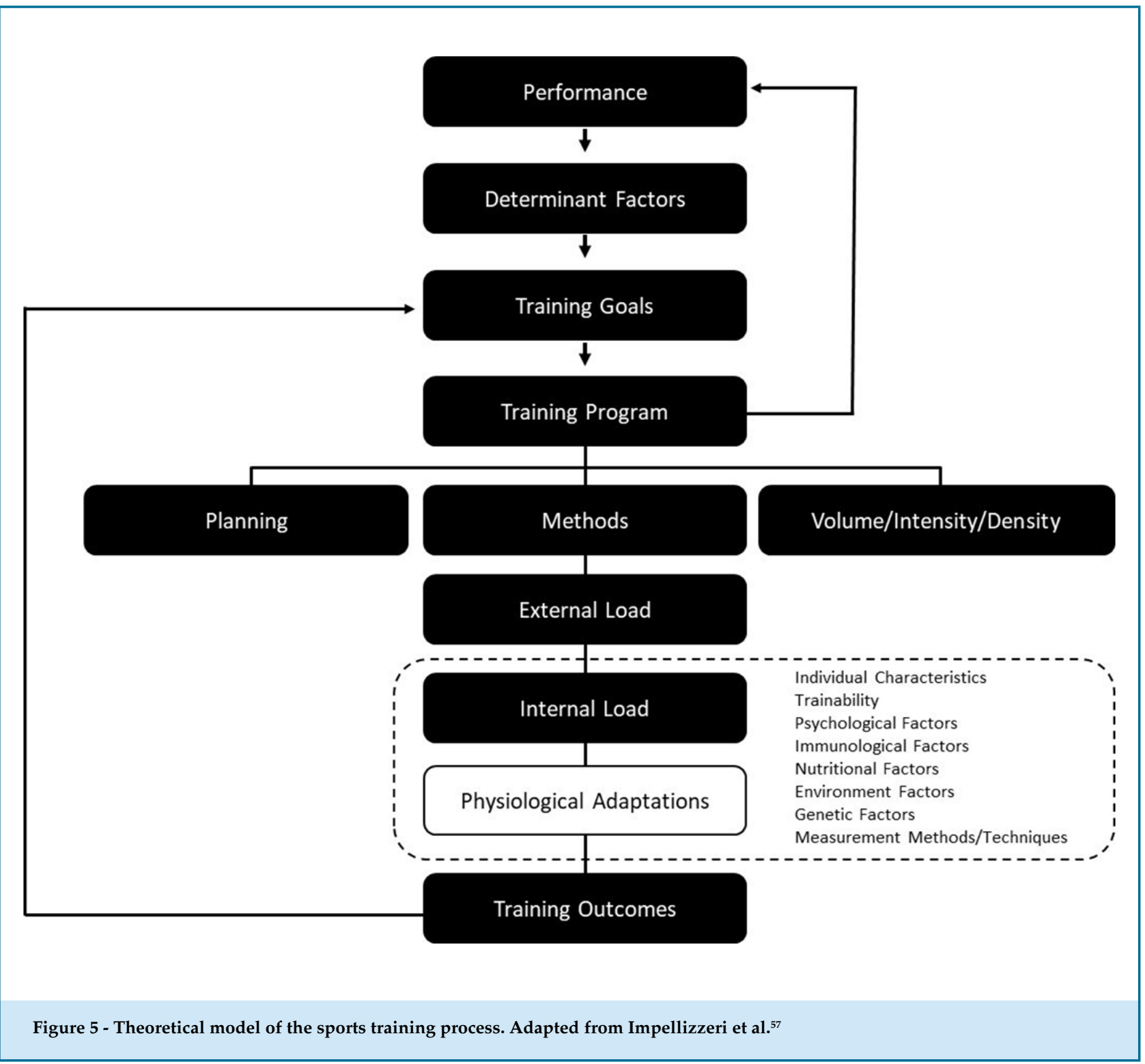

became easy to obtain instantaneous HR by measuring the duration of each cardiac cycle or the RR-interval. Therefore, these devices allowed the collection of data for analysis of both cardiac rhythm and changes of HR in short intervals and HR variability by mathematical techniques.

\section{Detection of cardiac arrhythmias}

Cardiac arrhythmias may occur without symptoms and thus, may not be perceived by the patients. This is common in clinically relevant arrhythmias. Thus, with the advent of digital technology, which facilitates realtime recording and storage of a great amount of data, and allows a fast, efficient transmission and even distance and real-time monitoring, there has been a growing interest in the use of monitors (some of them in the form of watches) and mobile apps for HR reading.

This subject was initially discussed in case reports, ${ }^{60,61}$ small studies, ${ }^{62,63}$ and data series, and more recently has been studied in epidemiological investigations including huge samples, ${ }^{64}$ that have benefited from machine learning and big data strategies. However, it is not the aim of this brief review to present a deeper discussion about this interesting theme.

It is worth noting that, due to a fast and encouraging progress, the possibility to correctly diagnose arrhythmias using monitors and smartphone apps has become more and more a reality in Cardiology. ${ }^{65}$ Also, very soon, with 
the improvement of algorithms, it will be possible to correctly detect artifacts and interferences, and thereby the rate of false negative and false positive diagnosis will tend to zero. At that time, these devices will be safely and reliably used in routine clinical practice and become a quality standard. But for now, the detection and recording of apparently abnormal HR values (higher or lower) particularly in high-intensity exercise, deserve careful, weighed, but not alarming consideration. This is even more relevant for asymptomatic, apparently healthy athletes and practitioners with a low cardiovascular risk. ${ }^{66}$

\section{HR variability}

As above mentioned, the large storage capacity of HR monitors has facilitated the measurement of instantaneous $H R$, i.e., of each cardiac cycle or the RR-interval, and thereby enabling the acquisition of data for analysis of $H R$ variability using mathematical techniques. ${ }^{67}$

One of the main contributions of exercise science about this topic occurred at the end of the $20^{\text {th }}$ century. Lima and $\mathrm{Kiss}^{68}$ proposed an indirect determination of lactate threshold by analysis of HR variability during maximal incremental exercise test. The physiological assumptions supporting this idea was based on the inverse relationship between parasympathetic autonomic activity and intensity of exercise. ${ }^{23}$ The authors used a HR monitor Polar NV Vantage (subsequently updated by the manufacturer as S810i, RS800, V800 and currently Vantage V). HR variability was defined as the mean of six measurements (taken every ten seconds) of the variation in consecutive RR intervals. The HR variability threshold was reached when the mean of the six measurements was lower than $3 \mathrm{~ms}$. This point was validated by the curve of blood lactate accumulation and corresponded to the lactate threshold.

Paschoa et al. ${ }^{69}$ evaluated HR kinetics during resistance exercise (unilateral leg extension) and observed a marked decrease of HR variability during exercise, even the shorter ones, with a fast recovery after exercise. More recently, Barbosa-Neto et al. ${ }^{56}$ showed that such HR variability response does not depend on exercise load. Similar RR-interval curves were found throughout the exercise performed at $50 \%, 80 \%$ and $100 \%$ of the load for 10 repetition maximum. Exercise cadence was controlled by a metronome, and thus all participants performed the repetitions (10 repetitions) in 15 seconds. Both studies used the Polar S810i monitor and performed the analysis of RR intervals.
Two recent systematic reviews showed that these portable devices have an acceptable margin of error ${ }^{70}$ and provide reliable and reproducible HR variability measurements. ${ }^{11}$ Therefore, they can be used for clinical and research purposes, especially considering its costbenefit relationship. ${ }^{70}$

\section{Four-second exercise test (T4s)}

Finally, another clinical application of HR measurement during exercise is the assessment of cardiac vagal tone. Considering that the rise in $\mathrm{HR}$ in the first four seconds of fast movement of the lower or upper limbs, ${ }^{71}$ be it active or passive ${ }^{72}$ depends solely on removal of vagal tone, Araújo et al. ${ }^{73,74}$ proposed the T4s. Briefly, the test consist in pedaling as fast as possible and without resistance a cycle ergometer from the fifth to the eighth second of a 12-second maximal inspiratory apnea. The quantification of the cardiac vagal index is determined by the ratio of two RR-intervals registered in the ECG: the longest RRinterval before exercise and the shortest RR-interval during exercise, which can be cycling ${ }^{73,75,76}$ or stationary running. ${ }^{.7}$ Recent studies have tested whether HR monitors could be used to determine this index and shown that HR monitor can be used as a surrogate for ECG to determine the cardiac vagal tone in the T4s using a cycle ergometer, ${ }^{78}$ but not in the T4s performed in orthostatic position. ${ }^{79}$

\section{Conclusions}

In summary, there is a wide range of monitors and smartphone apps to measure HR. The choice of the brand and model should be made based on the purpose of its use. Also, it is fundamental to know how to set up the device for personal, clinical or research purpose. These pieces of equipment may be helpful in the monitoring of the intensity of many types of exercises, and thereby increase the safety and efficacy of a physical exercise or sports training program. In addition, HR monitor devices and apps are in rapid development and would ultimately be useful in the detection of stress-induced cardiac arrhythmias and in the management and followup of physically active patients.

\section{Author contributions}

Conception and design of the research: Araujo CG. Acquisition of data: Almeida M, Bottino A, Ramos P, Araujo CG. Analysis and interpretation of the data: Almeida M, Bottino A, Ramos P, Araujo CG. Writing of 
the manuscript: Almeida M, Bottino A, Ramos P, Araujo CG. Critical revision of the manuscript for intellectual content: Almeida M, Bottino A, Ramos P, Araujo CG.

\section{Potential Conflict of Interest}

No potential conflict of interest relevant to this article was reported.

\section{Sources of Funding}

There were no external funding sources for this study.

\section{Study Association}

This study is not associated with any thesis or dissertation work.

\section{Ethics approval and consent to participate}

This article does not contain any studies with human participants or animals performed by any of the authors.

\section{References}

1. Frederix I, Caiani EG, Dendale P, Anker S, Bax J, Bohm A, et al. ESC e-Cardiology Working Group Position Paper: overcoming challenges in digital health implementation in cardiovascular medicine. Eur J Prev Cardiol. 2019: Mar 27:2047487319832394.

2. Jensen MT. Resting heart rate and relation to disease and longevity: past, present and future. Scand J Clin Lab Invest. 2019;79(1-2):108-16.

3. Nanchen D. Resting heart rate: what is normal? Heart. 2018;104(13):1048-9.

4. Almeida MB. Frequência cardíaca e exercício: uma interpretação baseada em evidências. Rev Bras Cineantopom Desempenho Hum. 2007;9(2):196-202.

5. Duarte CV, Myers J, de Araujo CG. Exercise heart rate gradient: a nove index to predict all-cause mortality. Eur J Prev Cardiol. 2015;22(5):629-35.

6. Ozemek C, Whaley MH, Finch WH, Kaminsky LA. Maximal heart rate declines linearly with age independent of cardiorespiratory fitness levels. Eur J Sport Sci. 2017;17(5):563-70.

7. Soares de Araujo CG, Duarte CV. Maximal heart rate in young adults: a fixed $188 \mathrm{bpm}$ outperforms values predicted by a classical age-based equation. Int J Cardiol. 2015 Apr 1;184:609-10.

8. Duarte CV, Araujo CG. Cardiac vagal index does not explain ageindependent maximal heart rate. Int J Sports Med. 2013;34(6):502-6.

9. Pesta D, Burtscher M. Importance of determining maximal heart rate for providing a standardized training stimulus. JAMA Intern Med. 2016;176(12):1883.

10. Vogel C, Wolpert C, Wehling M. How to measure heart rate? Eur J Clin Pharmacol. 2004;60(7):461-6.

11. Georgiou K, Larentzakis AV, Khamis NN, Alsuhaibani GI, Alaska YA, Giallafos EJ. Can wearable devices accurately measure heart rate variability? a systematic review. Folia Med (Plovdiv). 2018;60(1):7-20.

12. Silva DAS, Lima TR, Tremblay MS. Association between resting heart rate and health-related physical fitness in brazilian adolescents. Biomed Res Int. 2018 Jun 28;2018:3812197.

13. Kang SJ, Ha GC, Ko KJ. Association between resting heart rate, metabolic syndrome and cardiorespiratory fitness in Korean male adults. J Exerc Sci Fit. 2017;15(1):27-31.

14. Pittaras AM, Faselis C, Doumas M, Myers J, Kheirbek R, Kokkinos JP, et al. Heart rate at rest, exercise capacity, and mortality risk in veterans. Am J Cardiol. 2013;112(10):1605-9.

15. Zhang Y, Xu L, Zhang X, Yao Y, Sun Y, Qi L. Effects of differen durations of aerobic exercise on the cardiovascular health in untrained women: a meta-analysis and meta-regression. J Sports Med Phys Fitness. 2018;58(10):1525-36.

16. Jensen-Urstad K, Saltin B, Ericson M, Storck N, Jensen-Urstad M. Pronounced resting bradycardia in male elite runners is associated with high heart variability. Scand J Med Sci Sports. 1997;7(5):274-8.

17. Bahrainy S, Levy WC, Busey JM, Caldwell JH, Stratton JR. Exercise training bradycardia is largely explained by reduced intrinsic heart rate. Int J Cardiol. 2016 Nov 1;222:213-16.

18. Wingo JE, Ganio MS, Cureton KJ. Cardiovascular drift during heat stress: implications for exercise prescription. Exerc Sport Sci Rev. 2012;40(2):88-94

19. Araújo CGS. Respostas cardiorrespiratórias a um exercício submáximo prolongado. Arq Bras Cardiol. 1983;41(1):37-45.

20. Rowell L. Circulatory adjustments to dynamic exercise and heat stress: competing controls. In: Rowell L, editor. Human circulation: regulation during physical stress. New York: Oxford University Press; 1986.

21. Coyle EF, González-Alonso J. Cardiovascular drift during prolonged exercise: new perspectives. Exerc Sport Sci Rev. 2001;29(2):88-92.

22. Chagas TPN, Souza LMV, Santos T, Jesus BO, Dantas EHM, Prado ES. Impact of fluid replacement with coconut water on the hydration status and cardiovascular drift during exercise. J Phys Educ. 2017;28:e2804.

23. Almeida MB, Araújo CGS. Efeitos do treinamento aeróbico sobre a frequência cardíaca. Rev Bras Med Esporte. 2003;9(2):104-12.

24. Mourot L. Limitation of maximal heart rate in hypoxia: mechanisms and clinical importance. Front Physiol. 2018 Jul 23;9:972.

25. Brubaker P, Kitzman DW. Chronotropic incompetence: causes, consequences, and management. Circulation. 2011;123(9):1010-20.

26. Zweerink A, van der Lingen ACJ, Handoko ML, van Rossum AC, Allaart CP. Chronotropic incompetence in chronic heart failure. Circ Heart Fail. 2018;11(8):e004969.

27. Shen H, Zhao J, Zhou X, Li J, Wan Q, Huang J, et al. Impaired chronotropic response to physical activities in heart failure patients. BMC Cardiovasc Disord. 2017;17(1):136

28. Lauer MS, Okin PM, Larson MG, Evans JC, Levy D. Impaired heart rate response to graded exercise. Prognostic implications of chronotropic incompetence in the Framingham Heart Study. Circulation. 1996;93(8):1520-6.

29. Peçanha T, Silva-Júnior N, Forjaz CL. Heart rate recovery: autonomic determinants, methods of assessment and association with mortality and cardiovascular diseases. Clin Physiol Funct Imaging. 2014;34(5):327-39.

30. Cole CR, Blackstone EH, Pashkow FJ, Snader CE, Lauer MS. Heart-rate recovery immediately after exercise as a predictor of mortality. $\mathrm{N}$ Engl J Med. 1999;341(18):1351-7. 
31. Qiu S, Cai X, Sun Z, Li L, Zuegel M, Steinacker J, et al. Heart rate recovery and risk of cardiovascular events and all-cause mortality: a meta-analysis of prospective cohort studies. J Am Heart Assoc. 2017;6(5):pii: e005505.

32. Mendonca G, Teodósio C, Bruno P. Sexual dimorphism in heart rate recovery from peak exercise. Eur J Appl Physiol. 2017;117(7):1373-81.

33. Mattioli GM, Araújo CG. Association between initial and final transient heart rate responses in exercise testing. Arq Bras Cardiol. 2009;93(2):141-6.

34. Durmić T, Đjelić M, Gavrilović T, Antić M, Jeremić R, Vujović A, et al. Usefulness of heart rate recovery parameters to monitor cardiovascular adaptation in elite athletes: the impact of the type of sport. Physiol Int. 2019;106(1):81-94

35. Friel J. Total heart rate training: customize and maximize your workout using a heart rate monitor. Berkeley: Ulysses Press; 2006.

36. Burke E. Precision heart rate training for maximum fitness and performance. Champaign: Human Kinetics; 1998.

37. Lee ES, Lee JS, Joo MC, Kim JH, Noh SE. Accuracy of heart rate measurement using smartphones during treadmill exercise in male patients with ischemic heart disease. Ann Rehabil Med. 2017;41(1):129-37.

38. Bruining N, Caiani E, Chronaki C, Guzik P, van der Velde E, Task Force of the e-Cardiology Working. Acquisition and analysis of cardiovascular signals on smartphones: potential, pitfalls and perspectives: by the Task Force of the e-Cardiology Working Group of European Society of Cardiology. Eur J Prev Cardiol. 2014;21(2 Suppl):4-13.

39. Narasimha D, Hanna N, Beck H, Chaskes M, Glover R, Gatewood R, et al. Validation of a smartphone-based event recorder for arrhythmia detection. Pacing Clin Electrophysiol. 2018;41(5):487-94.

40. Garabelli P, Stavrakis S, Po S. Smartphone-based arrhythmia monitoring. Curr Opin Cardiol. 2017;32(1):53-7.

41. Coppetti T, Brauchlin A, Müggler S, Attinger-Toller A, Templin C, Schönrath F, et al. Accuracy of smartphone apps for heart rate measurement. Eur J Prev Cardiol. 2017;24(12):1287-93.

42. Sallis JF. Measuring physical activity: practical approaches for program evaluation in Native American communities. J Public Health Manag Pract. 2010;16(5):404-10.

43. Alger K. 6 best heart rate monitors: training with your heart is the fasttrack to your fitness gains.[ The Independent 21June 2018 [Internet] , [Cited in 2019 Jan 19]. Available from: https: / / www.independent.co.uk/ extras/indybest/gadgets-tech/best-heart-rate-monitors-track-workoutperformance-training-fitness-health-a8410191.html.

44. Cadmus-Bertram L, Gangnon R, Wirkus EJ, Thraen-Borowski KM, Gorzelitz-Liebhauser J. The accuracy of heart rate monitoring by some wrist-worn activity trackers. Ann Intern Med. 2017;167(8):607-8.

45. Cadmus-Bertram L, Gangnon R, Wirkus EJ, Thraen-Borowski KM, Gorzelitz-Liebhauser J. The accuracy of heart rate monitoring by some wrist-worn activity trackers. Ann Intern Med. 2017;166(8):610-2.

46. Singh J, Sittig DF. Accuracy of heart rate monitoring by some wrist-worn activity trackers. Ann Intern Med. 2017;167(8):607.

47. Boudreaux BD, Hebert EP, Hollander DB, Williams BM, Cormier CL, Naquin MR, et al. Validity of wearable activity monitors during cycling and resistance exercise. Med Sci Sports Exerc. 2018;50(3):624-33.

48. Araujo CG. Fast "ON" and "OFF" heart rate transients at different bicycle exercise levels. Int J Sports Med. 1985;6(2):68-73.

49. Horton JF, Stergiou P, Fung TS, Katz L. Comparison of Polar M600 optical heart rate and ECG heart rate during exercise. Med Sci Sports Exerc. 2017;49(12):2600-7.

50. Bai Y, Hibbing P, Mantis C, Welk GJ. Comparative evaluation of heart rate-based monitors: Apple Watch vs Fitbit Charge HR. J Sports Sci. 2018;36(15):1734-41.
51. Dooley EE, Golaszewski NM, Bartholomew JB. Estimating accuracy at exercise intensities: a comparative study of self-monitoring heart rate and physical activity wearable devices. JMIR Mhealth Uhealth. 2017;5(3):e34.

52. Reddy RK, Pooni R, Zaharieva DP, Senf B, El Youssef J, Dassau E, et al. Accuracy of wrist-worn activity monitors during common daily physical activities and types of structured exercise: evaluation study. JMIR Mhealth Uhealth. 2018;6(12):e10338

53. Eddolls WTB, McNarry MA, Stratton G, Winn CON, Mackintosh KA. High-intensity interval training interventions in children and adolescents: a systematic review. Sports Med. 2017;47(11):2363-74.

54. Latella C, Grgic J, Van der Westhuizen D. Effect of interset strategies on acute resistance training performance and physiological responses: a systematic review. J Strength Cond Res. 2019 Apr 1.

55. Alcaraz P, Sánchez-Lorente J, Blazevich A. Physical performance and cardiovascular responses to an acute bout of heavy resistance circuit training versus traditional strength training. J Strength Cond Res. 2008;22(3):667-71.

56. Barbosa-Netto S, Santos LM, Almeida MB. Effects of resistance exercise intensity on heart rate kinetics. R Bras Ci e Mov. 2015;23(1):88-94.

57. Impellizzeri FM, Marcora SM, Coutts AJ. Internal and external training load: 15 years on. Int J Sports Physiol Perform. 2019;14(2):270-3.

58. Vanrenterghem J, Nedergaard NJ, Robinson MA, Drust B. Training load monitoring in team sports: a novel framework separating physiological and biomechanical load-adaptation pathways. Sports Med. 2017;47(11):2135-42

59. Catapult [internet]. Introducing catapult vector: engineered for performance. 2019; [ Cited in 2019 Jan 19]. Available from: https: / / www. catapultsports.com/blog/introducing-catapult-vector-engineeredperformance.

60. Hunt D, Tanto P. Diagnosis of arrhythmias in athletes wearing heart rate monitors. J R Army Med Corps. 2017;163(3):224

61. Thabouillot O, Bostanci K, Bouvier F, Dumitrescu N, Stéfuriac M, Paule $\mathrm{P}$, et al. Syncope during competitive events: interrogating heart rate monitor watches may be useful! Prehosp Disaster Med. 2017;32(6):691-3.

62. Hwang J, Kim J, Choi KJ, Cho MS, Nam GB, Kim YH. Assessing accuracy of wrist-worn wearable devices in measurement of paroxysmal supraventricular tachycardia heart rate. Korean Circ J. 2019;49(5):437-45.

63. Koshy AN, Sajeev JK, Nerlekar N, Brown AJ, Rajakariar K, Zureik M, et al. Smart watches for heart rate assessment in atrial arrhythmias. Int J Cardiol. 2018 Sep 1;266:124-7.

64. Turakhia MP, Desai M, Hedlin H, Rajmane A, Talati N, Ferris T, et al. Rationale and design of a large-scale, app-based study to identify cardiac arrhythmias using a smartwatch: The Apple Heart Study. Am Heart J. 2019 Jan;207:66-75.

65. Falter M, Budts W, Goetschalckx K, Cornelissen V, Buys R. Accuracy of Apple Watch Measurements for heart rate and energy expenditure in patients with cardiovascular disease: Cross-Sectional Study. JMIR Mhealth Uhealth. 2019;7(3):e11889.

66. Gajda R, Biernacka EK, Drygas W. Are heart rate monitors valuable tools for diagnosing arrhythmias in endurance athletes? Scand J Med Sci Sports. 2018;28(2):496-516.

67. Barbosa MP, da Silva NT, de Azevedo FM, Pastre CM, Vanderlei LC. Comparison of Polar(R) RS800G3 heart rate monitor with Polar(R) S810i and electrocardiogram to obtain the series of RR intervals and analysis of heart rate variability at rest. Clin Physiol Funct Imaging. 2016;36(2):112-7.

68. Lima JRP, Kiss MAPM. Heart rate variability threshold. Rev Bras Ativ Fis Saúde. 1999;4(1):29-38

69. Paschoa DC, Coutinho JFS, Almeida M. Analysis of heart rate variability in strength testing. Rev SOCERJ. 2006;19(5):385-90. 
70. Dobbs WC, Fedewa MV, MacDonald HV, Holmes CJ, Cicone ZS, Plews DJ, et al. The accuracy of acquiring heart rate variability from portable devices: a systematic review and meta-analysis. Sports Med. 2019;49(3):417-35.

71. Silva BM, Vianna LC, Oliveira RB, Ricardo DR, Araujo CG. Similar cardiac vagal withdrawal at the onset of arm and leg dynamic exercise. Eur J Appl Physiol. 2008;102(6):695-701.

72. Nobrega AC, Araujo CG. Heart rate transient at the onset of active and passive dynamic exercise. Med Sci Sports Exerc. 1993;25(1):37-41.

73. Araujo CG, Nobrega AC, Castro CL. Heart rate responses to deep breathing and 4-seconds of exercise before and after pharmacological blockade with atropine and propranolol. Clin Auton Res. 1992;2(1):35-40.

74. Araújo CG, Nóbrega AC, Castro CL. Vagal activity: effect of age, sex and physical activity pattern. Braz J Med Biol Res. 1989;22(7):909-11.
75. Almeida MB, Ricardo DR, Araújo CGS. Heart rate variability in a truly maximum exercise testing. Rev SOCERJ. 2005;18(6):534-41.

76. Araújo CG, Castro CLB, Franca JF, Ramos PS. 4-second exercise test: reference values for ages 18-81 years. Arq Bras Cardiol. 2015;104(5):366-74

77. Almeida MB, Ricardo DR, Araújo CGS. Validation of the 4-Second Exercise test in the orthostatic position. Arq Bras Cardiol. 2004;83(2):155-9.

78. Pimentel AS, Alves ES, Alvim RO, Nunes RT, Costa CMA, Lovisi JCM, et al. Polar S810 as an alternative resource to the use of the electrocardiogram in the 4-second exercise test. Arq Bras Cardiol. 2010;94(5):580-4.

79. Silva B, Silva B, Wichi R, Oliveira J, Almeida M. Cardio-frequency meter does not replace EKG for orthostatic 4-second exercise test. Rev Bras Cardiol. 2012;25(5):377-83. 